\title{
Acute epiglottitis following traditional Chinese gua sha therapy
}

\author{
Keng-Kuang Tsai MD, Chih-Hung Wang MD PhD
}

Competing interests: None declared.

This article has been peer reviewed.

Affiliations: Department of Otolaryngology, Head and Neck Surgery, Tri-Service General Hospital, National Defense Medical Center (Tsai, Wang) and Songshan Branch (Tsai), Taipei,

Taiwan, Republic of China; and Graduate Institute of

Medical Sciences, National Defense Medical Center (Wang), Taipei, Taiwan, Republic of China.

Correspondence to: Chih-Hung Wang, chw@ms3.hinet.net

CMAJ 2014. DOI:10.1503 /cmaj.130919
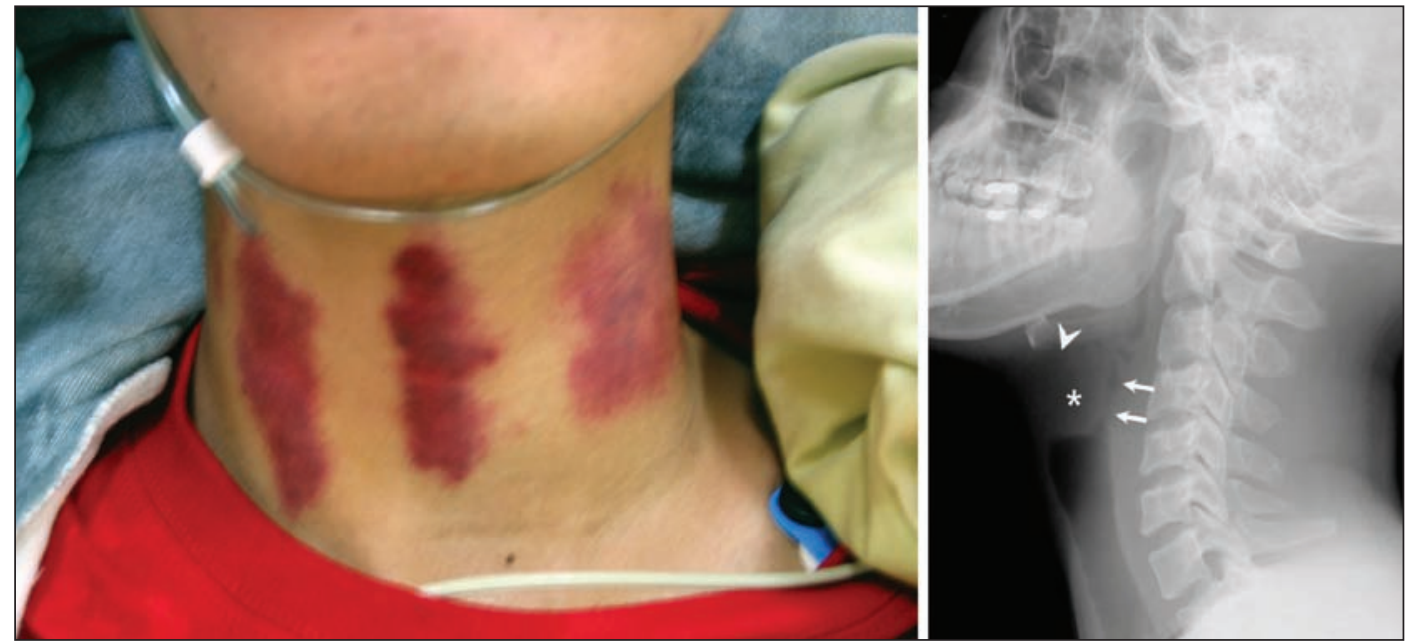

Figure 1: (A) Ecchymoses on the neck of a 23-year-old man after receiving traditional Chinese gua sha therapy for throat pain. (B) Radiograph of the patient's neck showing an elevated hyoid bone, swelling of the preepiglottic space (asterisk), a decrease in vallecular air space (the vallecula sign; arrowhead) and thickening of the retropharyngeal soft tissues (arrows) causing a narrowed airway.

A 23-year-old man presented to the emergency department with difficulty speaking after receiving traditional Chinese gua sha therapy on his neck (i.e., scraping of the skin) to treat throat pain that had lasted for two days.

On examination, the patient had clearly visible ecchymoses on the front and sides of his neck (Figure 1A). Although the patient was drooling, he was not in respiratory distress, and there was no stridor. He was afebrile, with normal vital signs. Laryngoscopy showed an enlarged epiglottis pushed against the posterior pharyngeal wall. A radiograph of the patient's neck showed an elevated hyoid bone and thickening of the retropharyngeal soft tissues (Figure 1B). We administered steroids intravenously, and the patient's dysphonia resolved within two hours. A subsequent laryngoscopic examination showed reduced swelling of the patient's epiglottis.

Epiglottitis, also called supraglottitis, is an inflammation of the epiglottis or supraglottic structures. Although usually related to bacterial infection, acute epiglottic swelling and airway obstruc- tion have also been linked to thermal injury and blunt trauma. ${ }^{1}$ Gua sha therapy involves repeated stroking, with pressure, over lubricated skin using a smooth-edged instrument, such as a spoon or coin. Inappropriate application of the procedure can cause a contusion injury to underlying soft tissue, ${ }^{2}$ as in our patient's case.

In our patient, the acute epiglottic swelling induced by gua sha appears to have involved injuries to the pre-epiglottic and retropharyngeal spaces, and a corresponding "vallecula sign" (i.e., poorly defined vallecula secondary to swelling of surrounding tissues) was seen, instead of a more typical radiographic "thumb sign" (i.e., thickening of the epiglottis). ${ }^{3}$

\section{References}

1. Parsons DS, Smith RB, Mair EA, et al. Unique case presentations of acute epiglottic swelling and a protocol for acute airway compromise. Laryngoscope 1996;106:1287-91.

2. Nielsen A. Gua sha research and the language of integrative medicine. J Bodyw Mov Ther 2009;13:63-72.

3. Ducic Y, Hebert PC, MacLachlan L, et al. Description and evaluation of the vallecula sign: a new radiologic sign in the diagnosis of adult epiglottitis. Ann Emerg Med 1997;30:1-6. 